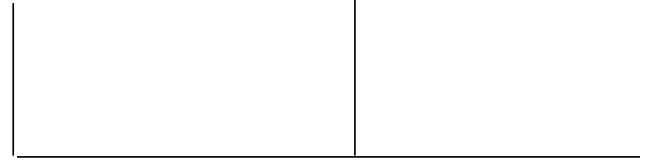

Rev. Latinoam. Psicopat. Fund., X, 1, 80-100

\title{
Estado atual da clínica psiquiátrica do transtorno obsessivo-compulsivo
}

\author{
Ana G. Hounie \\ Aline S. Sampaio \\ Ygor Ferrão \\ Maria Conceição do Rosário-Campos \\ Raquel Chilvarquer \\ Maria Eugênia de Mathis \\ Antonio Carlos Lopes \\ Maria Alice de Mathis \\ Christina Hajaj G onzáles \\ Anita Taub \\ Marcos Salem Vasconcelos \\ André A. A. Seixas \\ Antonio Reis de Sá Júnior \\ Eurípedes Miguel
}

Este artigo revisa a literatura sobre o transtorno obsessivocompulsivo com o objetivo de informar o estado atual da pesquisa científica nesse tema. Os autores citam a literatura internacional buscando enfatizar a pesquisa nacional, principalmente a pesquisa do seu grupo, o Projeto Transtornos do espectro Obsessivo-compulsivo.

Palavras-chave: Transtorno obsessivo-compulsivo, psicopatologia, comorbidade 


\section{Introdução}

O que hoje denominamos Transtorno Obsessivo-Compulsivo (TOC) começou a ser delineado pela psiquiatria francesa como um constructo clínico já no século XIX. A condição recebia denominações diversas segundo a interpretação do observador: Manie sans délire (Pinel, 1809), folie raisonnante (Ladame, 1890), idée fixes (Parchappe, 1850), idée irresistible (Brierre Boismont, 1851), délire de toucher (Ritti, 1879) e folie de doute (Marcé, 1862) (apud Berrios, 1989).

Enquanto os franceses enfatizaram a participação de fatores emotivos e volitivos no grupo dos doentes obsessivo-compulsivos, os psiquiatras alemães consideraram o problema uma alteração na esfera do intelecto e do julgamento (Griesenger, 1868 apud Stanford arquivo eletrônico). Westphal foi o primeiro a descrever a doença obsessivo-compulsiva de modo semelhante ao que atualmente é definido nos manuais psiquiátricos como TOC. Ele ressaltou a integridade da inteligência, a ausência de patologia afetiva, a inabilidade para suprimir os pensamentos intrusos e o reconhecimento da estranheza das representações, além de considerar a hereditariedade um fator etiológico importante (Westphal, 1878). Não havia, ainda, um consenso para designação da doença, sendo ora denominada de doença obsessiva, ora doença compulsiva. Embora Kraeplin já houvesse tipificado o atual TOC com o nome de "neurose obsessivocompulsiva”, o termo "transtorno obsessivo-compulsivo" emergiu de um consenso universal (Berrios, 1985).

Em 1903, com a publicação de Lês obsessions et la psychasthénie, Pierre Janet fez uma detalhada descrição de 325 pacientes obsessivos com idades entre 20 e 40 anos. Relacionou os sintomas obsessivo-compulsivos ao seu conceito de psicastenia, um conceito amplo com implicações etiológicas que incluía ainda tiques, fobias, estados confusionais e epilepsia. Esta publicação tem sido considerada até hoje uma das melhores descrições clínicas do atual conceito de TOC (Del Porto, 1994), e também pioneira na consideração de um “espectro” para este tipo de transtorno. 
Com o advento da psicanálise, Freud destacou a importância dessa entidade nosológica colocando-a ao lado da histeria (Freud, 1907; 1908; 1908a; 1909; 1913; 1915; 1918). Não sendo este trabalho um enfoque sobre a psicanálise do TOC, queremos ressaltar que a psicanálise deste transtorno também evoluiu, destacando-se também psicanalistas brasileiros neste campo, cuja contribuição pode ser apreciada nas coletâneas de artigos publicados pela Associação Psicanalítica de Porto Alegre (2003) e por Berlinck (2005). O objetivo do presente artigo é trazer à comunidade psicanalítica e de psicólogos o estado da arte no que se refere ao TOC, visto que existe superposição, embora certamente não completa, entre o TOC “da psiquiatria” e a "neurose obsessiva da psicanálise”. Procuramos, com isto, uma aproximação destes saberes, do qual um maior bemestar dos pacientes é nosso principal objetivo.

\section{O TOC hoje}

\section{Classificação nosográfica}

Após dois séculos de descrições fenomenológicas, o que permaneceu como conceito de TOC nas descrições atuais é a presença de obsessões e compulsões. Os instrumentos classificatórios dos transtornos mentais contribuíram sobremaneira para a uniformização de conceitos, a padronização de critérios diagnósticos, a instituição de tratamentos apropriados, além de facilitarem a pesquisa em psiquiatria. Lamentavelmente, do ponto de vista clínico, tais classificações tornam-se reducionistas.

O TOC é considerado hoje um transtorno crônico que afeta $2 \%$ da população mundial e está classificado no DSM-IV (Manual Diagnóstico de Doenças Mentais da Associação Americana de Psiquiatria, $4^{a}$ edição) entre os transtornos de ansiedade, sendo necessário para o diagnóstico que as obsessões ou compulsões causem sofrimento, consumam mais de uma hora por dia ou tragam prejuízo significativo na rotina, funcionamento ocupacional ou relacionamentos sociais do indivíduo.

Psicopatologia: obsessões, compulsões, fenômenos sensoriais, tiques

Obsessões são idéias, imagens ou impulsos intrusivos, repetitivos e estereotipados. Podem ser de vários tipos, como por exemplo medo de contaminação, medo de executar um ato de agressão contra um parente querido, pensamentos sobre a necessidade de guardar ou colecionar algo, obsessões que envolvam blas- 
fêmias e temas religiosos e obsessões com tema sexual. Já as compulsões são comportamentos ou atos mentais que o indivíduo é levado a executar voluntariamente, em resposta a uma obsessão, para reduzir a ansiedade e o mal-estar ou para prevenir algum evento temido. Elas ocorrem na tentativa de aliviar o incômodo causado pelos pensamentos obsessivos. São exemplos de compulsões: lavagem excessiva das mãos, banhos demorados e ritualizados, acúmulo de objetos sem importância sem conseguir jogá-los fora, repetições das atividades diárias, como, por exemplo, entrar e sair pela porta, ligar e desligar aparelhos eletrônicos, verificação de portas, janelas, gás, fogão para se certificar que está tudo em ordem. Estes são apenas alguns exemplos comuns, já que os temas e rituais podem ser bastante variados. Dada essa apresentação clínica marcadamente diversa, a hipótese é que o TOC seja um transtorno heterogêneo que pode ser dividido em alguns subgrupos. Desta forma, o TOC poderia ser classificado por apresentar algumas características distintas, como por exemplo, o TOC ligado à presença de tiques ou de fenômenos sensoriais (Miguel et al., 2005).

Os tiques podem ser de dois tipos: motores ou vocais. Os tiques motores são definidos como movimentos repentinos e breves, e os vocais como sons produzidos pela movimentação do ar através do nariz, boca ou garganta. Exemplos de tiques motores envolvem: piscar de olhos, movimentação de boca, língua e partes do rosto, movimentos de pescoço, tronco, braços e pernas. Já os tiques vocais englobam: tossir, pigarrear, fungar, assobiar, imitar sons de pássaros ou animais, repetir palavras ou sílabas, dizer palavras ou frases obscenas. Os tiques podem ocorrer isolados ou podem seguir uma orquestração, um tique vir seguido do outro. A Síndrome de Tourette (ST) é o transtorno caracterizado pela presença de tiques motores e vocais, com início antes dos 18 anos e duração mínima de um ano.

Os fenômenos sensoriais são experiências físicas que precedem ou acompanham os tiques ou compulsões. São didaticamente classificados em: fenômenos sensoriais físicos (sensações físicas focais ou generalizadas, táteis, músculo-esqueléticas ou viscerais) e fenômenos sensoriais mentais (sensações desconfortáveis, como premência ou urgência, "ter que” fazer inexplicável, sensação de incompletude, necessidade de descarregar uma energia mental, percepção de não estar “em ordem”) (ibid., 2001). Exemplos de fenômenos sensoriais são: sensação de partes do corpo com gordura ou óleo, o que leva a pessoa a se lavar até se livrar dessa sensação; sensação nos músculos, como “estofamento", que leva a pessoa a tensionar os músculos; sensação de que os objetos precisam estar visualmente "em ordem” e precisam ser arrumados; sensação de energia interna que vai crescendo e precisa ser descarregada com a realização de algum comportamento repetitivo; e necessidade ou premência de repetir. 


\section{Comorbidade com esquizofrenia e transtornos psicóticos}

O limite entre o transtorno psicótico e o TOC tem sido motivo de debate por várias décadas. Desde o início do século passado ocorrem relatos descrevendo os sintomas obsessivo-compulsivos (SOC) em pacientes esquizofrênicos, entretanto, não há conclusão em definitivo sobre uma possível associação (Rasmussen e Eisen, 1993; Welber e cols., 1976). Estudos recentes têm demonstrado que os pacientes esquizofrênicos com TOC ou SOC apresentam um funcionamento global pobre e uma grande deterioração neuropsiquiátrica (Hwang et al., 2000).

\section{Comorbidade com depressão e transtornos do humor}

Os Transtornos Depressivos foram descritos em cerca de $85 \%$ dos pacientes com TOC (Miguel et al., 1995; Rasmussen e Tsuang, 1986). Pacientes com TOC apresentam maiores escores de depressão, com uma tendência da depressão unipolar de surgir após o TOC, provavelmente secundário à sua gravidade (Miranda, 1999; Nestadt et al., 2003). O Transtorno Afetivo Bipolar (TAB) esteve presente em $7,3 \%$ dos pacientes, associado também à pior resposta ao tratamento com a clomipramina (Miguel et al., 2001). Outros estudos relatam taxas de $2 \%$ para TAB tipo I e 13,6\% para o tipo II (Perugi et al., 1997); 3\% para TAB tipo I e $8 \%$ para o tipo II (Hantouche et al., 2003) e 14,3\% para TAB tipos I e II combinados (Nestadt et al., 2003). Hantouche et al (2003) encontraram em 628 pacientes com TOC que a comorbidade com ciclotimia é comum (em torno de $50 \%$ ) e prediz uma pobre resposta a agentes antiobsessivos.

De acordo com o postulado pelo Grupo de Barcelona, é significativa a incompatibilidade de sintomas obsessivos com estados hipomaníacos ou maníacos. Os estados obsessivos, supostamente ancorados numa hipofunção do SNC e num mundo rígido de crenças, seriam impensáveis num contexto maníaco, onde impera uma hiperativação nervosa superior e um taquipsiquismo, com associações rápidas de idéias, humor expansivo e um mundo de crenças tão permissivo que permite o aparecimento de comportamentos instintivos que, num estado normal, permaneceriam controlados. Esses autores sugerem ainda que, num estado de euforia se dissipam as dúvidas, incluindo as normais, pois o paciente tem uma supervalorização de sua pessoa que mais o estimula para ações impulsivas do que para a reflexão e ruminação próprias do obsessivo. Se alguma compulsão permanece durante uma crise maníaca, provavelmente perde seu caráter angustiante e egodistônico, tornando-se tão-somente um ato automático e residual, ou seja, pode permanecer alguma característica de seu componente motor, mas o componente cognitivo (obsessões, dúvidas patológicas) e emocional (ansiedade) desaparecem na crise maníaca (Vallejo, 1995). 


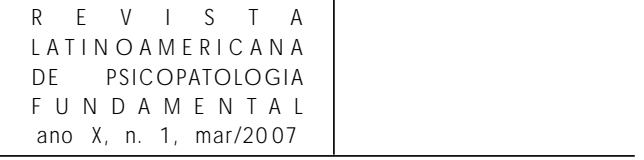

\section{Comorbidades com transtornos alimentares}

Ideações obsessivas e comportamentos ritualísticos são características freqüentes em pacientes com Transtornos Alimentares (TA). Um número considerável de pacientes com TA apresenta SOC primários suficientes para ser diagnosticado como TOC (Rothemberg, 1990). Von Ranson et al. (1999), avaliando 60 pacientes com diagnóstico de Bulimia, encontraram que 25\% preenchiam critérios para o diagnóstico de TOC. No sentido inverso, as taxas encontradas são menores: nos pacientes com TOC, os percentuais de TA variam de 8 a $17 \%$ (Rasmussen e Eisen, 1992), e de anorexia nervosa em 7,3\% (Shavitt et al., Clinical Features Associated with Treatment Response in Obsessive-Compulsive Disorder. Comprehensive Psychiatry, no prelo) tendendo a associar-se a uma menor resposta ao tratamento.

$\mathrm{Na}$ anorexia, os pacientes apresentam pensamentos monotemáticos ruminativos sobre o peso corporal, medo de virem a se tornar gordos, dietas, valor calórico dos alimentos e imagem corporal (Thiel et al., 1998). Essas ruminações tomam boa parte do tempo do paciente e os levam a evitar alimentos e a realizarem comportamentos ritualizados envolvendo o selecionar, comprar, preparar e comer os alimentos, por isso há quem considere a anorexia uma variável fenotípica do TOC. Tavares et al. (1996) salientam que pacientes com anorexia podem apresentar pensamentos ego-distônicos, como no TOC. Contudo, na maior parte dos casos, os pensamentos sobre comida e imagem corporal estão de acordo com a avaliação distorcida característica do transtorno, de que estão acima de seus pesos ideais, mesmo que se apresentem em estado de caquexia.

Tavares et al. (1996) sugerem que as três características psicopatológicas nucleares da bulimia seriam: 1) idéias supervalorizadas sobre a forma corporal, geralmente egossintônicas; 2) desejo de comer e perda do controle deste impulso e 3) culpa após a perda do controle dos impulsos e gestos reparadores ou compensadores do ato (purgação, jejum, exercícios etc.). Os pacientes bulímicos parecem apresentar maior freqüência de obsessões com cunho agressivo, bem como maior tendência a atos impulsivos (por exemplo: automutilação, tentativas de suicídio), comparados a pacientes com anorexia (Matsunaga et al., 1999).

\section{Comorbidade com transtorno dismórfico corporal}

Apesar de bem descrito há mais de cem anos e de causar muito sofrimento, estima-se que apenas cerca de $10 \%$ dos pacientes com TDC (antes chamado dismorfofobia) receba atendimento apropriado (Phillips et al., 2001). Os portadores tendem a procurar dermatologistas ou cirurgiões plásticos retardando o diagnóstico. 
O conceito de TDC é fundamentado numa distorção cognitiva que pode se manifestar como preocupação, obsessão, idéia supervalorizada ou delirante a respeito da forma do corpo ou partes dele (Torres et al., 2005). O TDC está atualmente classificado no DSM-IV como um dos Transtornos Somatoformes, mas tem sido relacionado ao espectro obsessivo-compulsivo, por compartilhar características fenomenológicas descritivas com o TOC (Hollander e Wong, 1995; McElroy et al., 1994; Frare et al., 2004). Muitos casos, na realidade, mostram comorbidades entre TDC e TOC. Frare et al. (2004) compararam 34 pacientes com TDC, 79 com TOC e 24 com a comorbidade e encontraram: distribuição igual entre os sexos; idade de início mais precoce para os grupos com TDC; maior prevalência de comorbidade com transtorno bipolar, fobia social, bulimia e transtornos relacionados ao uso e abuso de substâncias no grupo com TDC + TOC. A presença de TOC comórbido não alterou a forma dos sintomas do TDC, a não ser por uma freqüência maior de acometimento da região da face nos pacientes com TDC puro. Alguns autores consideram que uma das diferenças entre as duas condições seria o menor juízo crítico sobre seus sintomas em pacientes com TDC (Eisen et al., 2004).

Comorbidade com transtorno de tiques e a síndrome de Tourette

A ocorrência de tiques foi relatada em 7 a $20 \%$ de crianças em idade escolar com TOC (Coffey et al., 1998). Ferrão et al. (Clinical Features Associated with Treatment-Refractory Obsessive-Compulsive Disorder - submetido) encontraram num grupo de pacientes refratários ao tratamento do TOC 17,4\% de comorbidade com ST, estando de acordo com o estudo de Coffey et al., mas o achado de 3,8\% dessa comorbidade para os respondedores está bem abaixo do esperado. Rasmussen e Eisen (1992) encontraram apenas cerca de 7\% de pacientes com comorbidade entre TOC e ST. TOC de início precoce parece ser um subgrupo em particular apresentando maior associação com tiques e Síndrome de Tourette e maior agregação familiar (Rosário-Campos et al., 2005).

\section{Teorias etiopatogênicas}

As causas do TOC ainda não são conhecidas. Acredita-se atualmente no modelo misto, que descreve a combinação entre fatores hereditários e genéticos a fatores ambientais (Miguel et al., 2005). 


\section{$\begin{array}{lllllll}R & E & V & \text { I } & S & T & A\end{array}$ \\ LATINOAMERICAN A \\ DE PSICO PATO LOGIA \\ F U N D A M E N T A L \\ ano $X$, n. $1, \operatorname{mar} / 2007$}

\section{Fatores genéticos no transtorno obsessivo-compulsivo}

O envolvimento de fatores genéticos na etiologia do TOC vem sendo enfatizada desde as primeiras descrições do quadro (Pitman, 1984). Os genes responsáveis pelos transtornos psiquiátricos sofrem influências diversas, e têm sua expressividade modificada por fatores ambientais, fazendo-se crer que o TOC obedeça a uma herança genética não-mendeliana ou “complexa” (Hounie, 2003).

Vários estudos de famílias têm fornecido evidências irrefutáveis de que o TOC é familial (Lenane et al., 1990; Black et al., 1992; Pauls et al., 1995; Nestadt et al., 2000a; Gonzalez, 2003; Rosário-Campos et al., 2005). Uma meta-análise publicada recentemente, envolvendo cerca de 312 probandos e 1.209 familiares de primeiro grau de probandos com TOC, confirma esta hipótese (Hettema et al., 2001). Dentre todos os estudos de famílias publicados, estes autores incluíram em sua análise os quatro estudos com o maior rigor metodológico (Black et al., 1992; Fyer et al., 1993, citado em Rasmussen, 1993; Pauls et al., 1995; Nestadt et al., 2000a), e outro que não realizou entrevistas cegas (McKeon e Murray, 1987). Hettema et al. (2001) relataram um risco agregado de $8,2 \%$ entre os familiares “caso" e de $2 \%$ entre os familiares "controle”, com uma razão de chance (odds ratio) de 4 (95\% IC = 2,2-7,1). No Brasil, o primeiro estudo de famílias com TOC avaliou 30 pacientes adultos com TOC e 173 familiares em primeiro grau, comparados a 348 familiares em primeiro grau de 42 probandos “controle” (Gonzalez, 2003). Após correção para idade, as freqüências para TOC e SOC foram $8,1 \%$ e $22,1 \%$, respectivamente, para familiares de pacientes com TOC e $1,8 \%$ e $3,9 \%$ nos familiares do grupo controle. Os riscos mórbidos corrigidos para TOC e SOC foram de 40,3\% entre os familiares de probandos com início dos SOC antes dos 14 anos de idade (início precoce) e de 21,1\% entre os familiares dos probandos com início do quadro após os 17 anos de idade. Nesse estudo, ainda, os transtornos de tiques, transtorno dismórfico corporal (TDC) e transtorno da compulsão alimentar periódica também foram mais prevalentes entre familiares “caso” do que entre os familiares “controle”. Dentre os familiares-caso, os familiares de pacientes com TOC de início precoce apresentaram maior risco de desenvolver transtornos de tiques.

Revisando estudos com gêmeos monozigóticos, Rasmussen e Tsuang (1984) encontraram em 21 pares uma taxa de concordância de 62\%. Carey e Gottesman (1981) estudaram 15 pares de gêmeos monozigóticos e 15 pares de gêmeos dizigóticos, encontrando taxas de concordância de 87\% para "neurose obsessiva” para os primeiros, e $47 \%$ para os segundos. Como a concordância entre os gêmeos monozigóticos está abaixo dos 100\%, esses estudos mostram que outros fatores (i.e. ambientais, socioculturais, pré e perinatais) também têm um papel importante na manifestação dos SOC. 
Dos sete estudos atuais testando possíveis padrões de transmissão do TOC em famílias por análise de segregação, cinco foram realizados a partir de indivíduos com TOC (Nicolini et al., 1991; Alsobrook et al., 1999; Cavalini et al., 1999; Nestadt et al., 2000b; Hanna et al., 2005), um foi realizado em famílias de indivíduos com transtornos alimentares (Cavalini et al., 2000) e um com famílias de indivíduos com ST (Leckman et al., 2003). Esses estudos sugerem que genes diferentes parecem influenciar a expressão do TOC, porém não foram suficientemente conclusivos, devido a amostragens pequenas e heterogeneidade fenotípica dos probandos (Pato et al., 2002).

As análises de ligação (Kruglyak e Lander, 1995) sugerem ligação no cromossomo 9p (Hanna et al., 2002; Willour et al., 2004).

Genes candidatos para TOC são testados segundo a sua freqüência em relação a um grupo controle (Cantor e Rotter, 1992; Pato et al., 2002), e por via deste procedimento os escolhidos para investigação são os genes do sistema serotonérgico, devido à eficácia dos inibidores seletivos da recaptação de serotonina (ISRS) no tratamento dos pacientes com TOC. A freqüente associação entre a ST e o TOC, e a eficácia dos antipsicóticos no tratamento de pacientes com TOC resistente, levantaram hipóteses de que genes do sistema dopaminérgico poderiam também estar envolvidos. Outros genes candidatos que também vêm sendo investigados são genes dos receptores de glutamato (Delorme et al., 2004), do fator neurotrófico derivado do cérebro (Hall et al., 2003), do receptor microopióide (Urraca et al., 2004), da glicoproteína oligodendrocítica da mielina (Zai et al., 2004) e do GABA B1 (Zai et al., 2005). Meira-Lima et al. (2004) encontraram diferenças nas freqüências das distribuições genotípicas dos polimorfismos C516T do gene do receptor de serotonina tipo 2A (5HT2A), sugerindo que esta variante do gene possa representar um risco para desenvolver TOC nesta casuística.

\section{Fatores epigenéticos}

Dentre os fatores epigenéticos que poderiam estar associados ao TOC estão fatores perinatais, infecções, lesões do SNC, eventos traumáticos, processos hormonais e inflamatórios. Kano et al. (2001) encontraram que o uso de fórceps, sofrimento fetal ou parto prematuro poderiam ser fatores de risco perinatais para o TOC, independentes da vulnerabilidade genética. Vasconcelos et al. (Pre, peri and postnatal risk factors and obsessive-compulsive disorder - submetido) encontraram, como fatores de risco associados ao TOC, edema na gestação e parto prolongado. Lesões de SNC envolvendo gânglios da base (Carmin et al., 2002), região frontal posterior direita (Swoboda e Jenike, 1995), região parietal inferior direita (Simpson e Baldwin, 1995), entre outras áreas levaram ao aparecimento de sintomas obsessivo-compulsivos. 
relacionado especificamente a experiências traumáticas, diversos estudos sugerem que o TOC pode também ter esta associação, por mecanismos ainda não elucidados. Entretanto, a ligação entre trauma e TOC foi reconhecida por Janet e Raymund (1976), que sugeriram que o tipo de "TOC adquirido" era causado por choque emocional. O TOC tem sido ligado a eventos estressantes tais como aumento de responsabilidade (nascimento de um filho ou promoção de emprego) ou perdas significativas (morte de um membro da família ou perda de emprego) (Rasmussen e Tsuang, 1986). Sasson et al. (2005) estudaram alguns casos de militares israelenses diagnosticados com TOC e transtorno de estresse póstraumático (TEPT) e encontraram que a instalação do TOC estava claramente associada a trauma. Pitman (1993) relatou o caso de um soldado que desenvolveu TOC e TEPT depois de uma experiência de combate no Vietnã. Seus SOC foram compreendidos como uma busca mágica para o controle de eventos incontroláveis. Horowitz (1975) encontrou que condições de estresse exercem um poderoso efeito em relação ao aumento da freqüência de pensamentos intrusivos, uma tendência das memórias do evento traumático retornarem à consciência, o que pode tornar-se muito desconfortável, não somente em pacientes psiquiátricos, mas também em indivíduos normais. Rajarethinam e cols (2000) relataram dois casos de TOC com início abrupto e duração breve sucedendo estresse psicológico e fisiológico num contexto de doença clínica. Os dois casos ocorreram em mulheres com 54 e 48 anos, sem passado psiquiátrico, que desenvolveram rituais de limpeza e medo de contaminação associados, respectivamente, a leucemia mielóide aguda e lipossarcoma retroperitonial. Quando as pacientes entenderam mais sobre seu quadro clínico, os sintomas desapareceram. A rápida resolução dos sintomas nestes casos levantou a hipótese do TOC poder desenvolver-se agudamente, seguindo um fator desencadeante compreensível, podendo ter uma evolução diferente, menos crônica do que o TOC tradicional, mesmo se os sintomas forem graves.

Gravidez e puerpério foram também implicadas como fatores de risco para instalação do TOC ou exacerbação de TOC pré-existente (Buttolph e Holland, 1990). TOC associado ao puerpério foi relatado por Sichel et al. (1993), e a ocitocina relacionada ao desencadeamento não apenas de SOC, mas também de TOC (Maina et al., 1999). Também foi encontrada associação com aborto. Geller et al. (2001) encontraram que as mulheres que sofreram aborto tinham um risco maior de desenvolver um primeiro episódio de TOC ou recorrência de um TOC preexistente, pelo menos nos seis meses de seguimento da pesquisa.

A importância em determinar a influência de fatores ambientais no desencadeamento e evolução do TOC é de fundamental relevância, já que fatores ambientais são passíveis de intervenção e mesmo de prevenção. É possível que 


\begin{tabular}{lccccc|l}
$R$ & $E$ & $V$ & I & $S$ & $T$ & $A$ \\
LATIN O A M E RIC AN A & \\
DE PSICO PATO LOGIA & \\
F U N D D A M E N T A L & \\
ano & $X$, & n. & 1, & mar/2007 & \\
\hline
\end{tabular}

alguns subtipos de TOC sejam mais susceptíveis a influências ambientais enquanto outros subtipos teriam maior carga genética.

\section{Fatores neuro-anatômicos e neuropsicológicos}

O sistema fronto-estriado-talamo-cortical (FSTC) tem sido implicado na etiologia de um grupo de doenças neuropsiquiátricas como a ST, o TOC, Transtorno de Déficit de Atenção com/sem Hiperatividade (TDAH), Depressão, Esquizofrenia e Autismo (Bradshaw, 2001). Circuitos neurais interligando áreas corticais (giros órbito-frontais, giro do cíngulo), gânglios da base (núcleo caudado, principalmente) e tálamo médio dorsal têm sido considerados importantes na fisiopatologia destes transtornos (Graybiel et al., 2000). Além disso, soc estão presentes em transtornos neurológicos como Coréia de Sydenham, ST, Parkinson pós-encefalítico e epilepsias do lobo temporal, reforçando ainda mais a implicação das estruturas que compõem o circuito FSTC cortical na gênese destes sintomas.

Além dos métodos de investigação por imagem, tais como SPECT (tomografia por emissão de fóton único), a neuropsicologia, através de técnicas de avaliação do desempenho cognitivo destes pacientes, permite aferir áreas ou circuitos cerebrais disfuncionais e, portanto, tem sido reconhecida como um método válido para compreender os substratos neuro-anatômicos envolvidos em patologias neuropsiquiátricas. De acordo com Savage et al. $(1999,2000)$ a habilidade de fixar informações está preservada nos pacientes com TOC, sendo suas dificuldades de evocação secundárias a uma inabilidade de empregar estratégias de organização eficientes. Estudos de déficits de funções executivas não foram consistentes, provavelmente devido a pouca sensibilidade dos instrumentos disponíveis para a avaliação das várias facetas desse complexo conjunto de habilidades (Kuelz et al., 2004).

\section{Relação entre TOC e personalidade anancástica}

Crianças com TOC e outros transtornos ansiosos apresentaram escores mais elevados nos traços de esquiva a danos (Gothelf et al., 2004). A questão que se coloca aqui é se uma personalidade obsessiva pré-mórbida estaria sempre presente e seria um fator necessário para o desenvolvimento do TOC.

No nosso meio, Torres (1994) estudou comorbidade entre TOC e transtornos de personalidade (TP), tendo encontrado prevalências de TP evitativo (52,5\%), de- 
pendente (40\%), histriônico (20\%), paranóide (20\%), anancástico $(17,5 \%)$, narcisista (7,5\%), esquizotípico (5\%), passivo-agressivo (5\%) e autodestrutivo (5\%).

Outro estudo sugere que o DSM-IV não distingue o TOC do transtorno de personalidade obsessiva, dada a confusão conceitual entre os critérios de ambos os transtornos (Mckay e al., 1996; Ricciardi et al., 1992). O estudo da relação entre TOC e transtorno obsessivo de personalidade, portanto, continua em aberto.

\section{Conclusão}

O conhecimento público e científico acerca do TOC tem se ampliado ao longo dos anos. Devido ao TOC ser um transtorno heterogêneo, os estudos nesta área tentam definir subgrupos, na tentativa de elucidar as suas bases etiopatogênicas.

Agradecimentos

Agradecemos ao Dr. Fernando Portela Câmara, da Universidade Federal do Rio de Janeiro, pela leitura cuidadosa do artigo e suas valiosas contribuições.

Referências

Alsobrook, J. P. et al. Segregation analysis of obsessive-compulsive disorder using symptom-based factor scores. Am. J. Med. Genet., v. 88, p. 669-75, 1999.

American Psychiatric Association. Diagnostic and Statistical Manual of Mental Disorders. Fourth edition, Washington, D.C., 1994.

Associação Psicanalítica de Porto Alegre (org.). A necessidade da neurose obsessiva. Porto Alegre: APPOA, 2003.

Berlinck, Manoel Tosta (org.). Obsessiva neurose. São Paulo: Escuta, 2005.

Berrios, G. E. Obsessional disorders during the 19th century: terminological and classificatory issues. In: Anatomy of Madness. London: Tavistock Publications, 1985. v. I.

Obsessive-compulsive disorder: its conceptual history in France during the $19^{\text {th }}$ century. Compr. Psychiatry. v. 30, n. 4, p. 283-95, Jul.-Aug./1989.

Black, D.W. et al. A family study of obsessive-compulsive disorder. Arch Gen Psychiatry, v. 49, p. 362-8, 1992. 


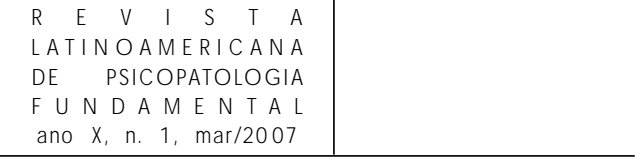

Bradshaw, J. L. Developmental disorders of the frontostriatal system. Brain Damage: Behaviour and Cognition Series, 2001.

Buttolph, J. L. e Holland, A. D. Obsessive-compulsive disorders in pregnancy and childbirth. In: Baer, M. e Minichiello, W. E. (eds.). Obsessive-Compulsive Disorders: Theory and Management. St. Louis: Yearbook Medical Publishers, 1990. p. 89-95.

Cantor, R. M. e Rotter, J. I. Analysis of genetic data: methods and interpretation. In: King, R. A.; Rotter, J. I.; Motulsky, A. G. e King, L. (eds.). The Genetic Basis of Common Diseases. Oxford University Press, 1992. p. 49-70.

Carey, G. e Gottesman, I. I. Twin and family studies of anxiety, phobic and obsessive disorders. In: Klien, D. F. e Rabkin, J. (eds.). Anxiety: New Research and Changing Concepts. New York: Raven Press, 1981. p. 117-36.

Carmin, C. N. et al. Treatment of late-onset OCD following basal ganglia infarct. Depress Anxiety, v. 15, n. 2, p. 87-90, 2002.

Cavalini, M. C. et al. Complex segregation analysis for obsessive-compulsive disorder and related disorders. Am. J. Med. Genet., v. 88, p. 38-43, 1999.

Complex segregation analysis of obsessive-compusive disorder in 141 families of eating disorder probands, with and without obsessive-compulsive disorder. Am. J. Med. Genet., v. 96, p. 384-91, 2000.

Coffey, B. J. et al. Tourette's disorder and related problems: a review and update. Harv. Rev. Psychiatry, v. 2, n. 3, p. 121-32, 1994.

Tourette's disorder with and without obsessive-compulsive disorder in adults: are they different? Nerv. Ment. Dis., v. 186, n. 4, p. 201-6, 1998.

Del Porto, J. A. Distúrbio obsessivo-compulsivo: fenomenologia clínica de 105 pacientes e estudo de aspectos trans-históricos e trans-culturais. 1994. Tese. Escola Paulista de Medicina, São Paulo.

DeLorme, R. et al. Frequency and transmission of glutamate receptors GRKI2 and GRKI3 polymorphisms in patients with obsessive-compulsive disorder. Neuroreport, v. 15, p. 699-702, 2004.

EISEN, J. L. et al. Insight in obsessive compulsive disorder and body dysmorphic disorder. Compr. Psychiatry, v. 45, n. 1, p. 10-5, 2004.

Eley, T. C. e Stevenson, J. Specific life events and chronic experiences differentially associated with depression and anxiety in young twins. J. Abnorm. Child Psychol., v. 28, n. 4, p. 383-94, Aug./2000.

Frare, F. et al. Obsessive-compulsive disorder and body dysmorphic disorder: a comparison of clinical features. Eur. Psychiatry, v. 19, n. 5, p. 292-8, 2004. 
Freud, S. (1907). Atos obsessivos e práticas religiosas. In: Edição Standard Brasileira das Obras Psicológicas Completas de Sigmund Freud. Rio de Janeiro: Imago, 1969. v. IX.

(1908). Caráter e erotismo anal. In: Edição Standard Brasileira das Obras Psicológicas completas de Sigmund Freud. Rio de Janeiro: Imago, 1969. v. IX.

(1908a). Moral sexual “civilizada” e doença nervosa moderna. In: Edição Standard Brasileira das Obras Psicológicas Completas de Sigmund Freud. Rio de Janeiro: Imago, 1969. v. IX.

(1909). Notas sobre um caso de neurose obsessiva. In: Edição Standard Brasileira das Obras Psicológicas Completas de Sigmund Freud. Rio de Janeiro: Imago, 1969. v. X.

(1913). Totem e tabu. In: Edição Standard Brasileira das Obras Psicológicas Completas de Sigmund Freud. Rio de Janeiro: Imago, 1969. v. XIII.

(1915). Neuroses de transferência: uma síntese. Trad. de Abram Eksterman. Rio de Janeiro: Imago, 1987.

(1918). A neurose obsessiva in História de uma neurose infantil. In: Edição Standard Brasileira das Obras Psicológicas Completas de Sigmund Freud. Rio de Janeiro: Imago, 1969. v. XVII, p. 71-80.

Geller, P. A. et al. Anxiety disorders following miscarriage. J. Clin. Psychiatry., v. 62, p. 432-8, 2001.

Gonzalez, C. H. Estudo de famílias no transtorno obsessivo-compulsivo. 2003. 227p. Tese. Universidade Federal de São Paulo, São Paulo.

Gothelf, D. et al. Life events and personality factors in children and adolescents with obsessive-compulsive disorder and other anxiety disorders. Comprehensive Psychiatry, v. 45, n. 3, p. 192-8, May-June/2004.

Graybiel, A. M. e Rauch, S. L. Toward a neurobiology of obsessive-compulsive disorder. Neuron., v. 28, n. 2, p. 343-7, Nov./2000.

HaLL, D. et al. Sequence variants of the brain-derived neurotrophic factor (BNDF) gene are strongly associated with obsessive-compulsive disorder. Am. J. Hum. Genet., v. 73, p. 370-6, 2003.

Hanna, G. L. et al. Genome-wide linkage analysis of families with obsessive-compulsive disorder ascertained through pedriatric probands. Am. J. Med. Genet., v. 114, p. 54152, 2002.

Complex segregation analysis of obsessive-compulsive disorder in families with pediatric probands. Hum. Hered., v. 60, p. 1-9, 2005.

Hantouche, E. G. et al. Cyclothymic OCD: a distinct form? J. Affect Disord., v. 75, n. 1, p. 1-10, 2003. 
Hettema, J. M. et al. A review and meta-analysis of the genetic epidemiology of anxiety disorders. Am. J. Psychiatry., v. 158, p. 1568-78, 2001.

Hollander, E. e Wong, C. M. Obsessive-compulsive Spectrum Disorders. J. Clin. Psychiatry., v. 56, suppl. 4, p. 3-6, 1995.

Horowitz, M. J. Intrusive and repetitive thoughts after experimental stress. A summary. Arch. Gen. Psychiatry., v. 32, n. 11, p. 1457-63, Nov./1975.

Hounie, A.G. Transtornos do espectro obsessivo-compulsivo e febre reumática: um estudo de transmissão familiar. 2003. 174p. Tese. Faculdade de Medicina da Universidade de São Paulo, São Paulo.

Hounie, A.G. et al. Obsessive-compulsive spectrum disorders in rheumatic fever with and without Sydenham's chorea. J. Clin. Psychiatry., v. 65, n. 7, p. 994-9, Jul./2004.

Hwang, M.Y. et al. Clinical and neuropsychological profiles of obsessive-compulsive schizophrenia: a pilot study. J. Neuropsychiatry Clin. Neurosci., v. 12, n. 1, p. 91-4, 2000 Winter.

Kano, Y. et al. A family study of Tourette syndrome in Japan. Am. J. Med. Genetics, v. 105, p. 414-21, 2001.

Kruglyak, L. e Lander, E. Complete multipoint sib-pair analysis of qulitative and quantitative traits. Am. Hum. Genet., v. 57, p. 439-54, 1995.

Kuelz, A. K. et al. Neuropsychological performance in obsessive-compulsive disorder: a critical review. Biol. Psychol., v. 65, n. 3, p. 185-236, Feb./2004.

Leckman, J. F. et al. Obsessive-compulsive symptom dimensions in affected sibling pairs diagnosed with Gilles de la Tourette syndrome. Am. J. Med. Genet. B. Neuropsychiatr. Genet., v. 116, p. 60-8, 2003.

Lenane, M. C. et al. Psychiatric disorders in first-degree relatives of children and adolescent with obsessive-compulsive disorder. J. Am. Acad. Child Adolesc. Psychiatry, v. 29, p. 407-12, 1990.

Lochner, C. et al. Childhood trauma in obsessive-compulsive disorder, trichotillomania and controls. 2002. <http://www.interscience.wiley.com>.

MAINA, G. et al. Recent life events and obsessive-compulsive disorder (OCD): the role of pregnancy/delivery. Psychiatry Res., v. 89, n. 1, p. 49-58, 1999.

Matsunaga, H. et al. A comparision of clinical features among Japanese eatingdisordered women with obsessive-compulsive disorder. Comp. Psychiatry, v. 40, n. 5, p. 337-42, 1999.

McElroy, S. L. et al. Obsessive compulsive spectrum disorder. J. Clin. Psychiatry., v. 55, suppl., p. 33-51, discussion p. 52-3, 1994.

Mckay, D. e Neziroglu, F. Social skills training in a case of obsessive-compulsive 
disorder with schizotypal personality disorder. J. Behav. Ther. Exp. Psychiatry, v. 27, n. 2, p. 189-94, Jun./1996.

McKeon, J. et al. Life events and personality traits in obsessive-compulsive neurosis. Br. J. Psychiatry, v. 144, p. 185-9, Feb./1984.

McKeon, P. e Murray, R. Familial aspects of obsessive-compulsive neurosis. Brit. J. Psychiatry, v. 151, p. 528-34, 1987.

MeirA-Lima, I. et al. Association analysis of the catechol-o-methyltransferase (COMT), serotonin transporter (5-HTT) and serotonin 2A receptor (5HT2A) gene polymorphisms with obsessive-compulsive disorder. Genes. Brain. Behav., v. 3, p. 75-9, 2004.

Mercadante, M. T. et al. Obsessive-compulsive spectrum disorders in rheumatic fever patients. J. Neuropsychiatry Clin. Neurosci., v. 17, n. 4, p. 544-7, 2005 Fall.

Miguel, E. C. et al. Phenomenology of intentional repetitive behaviors in obsessivecompulsive disorder and Tourette's disorder. J. Clin. Psychiatry, v. 56, n. 6, p. 24655, 1995.

The tic-related obsessive-compulsive disorder phenotype and treatment implications. Adv. Neurol., v. 85, p. 43-55, 2001.

Obsessive-compulsive disorder phenotypes: implications for genetic studies. Mol. Psychiatry., v. 10, n. 3, p. 258-75, mar./2005.

Miranda, M. A. Transtorno obsessivo-compulsivo e comorbidade - Um estudo casocontrole. 1999, 181p. Tese. Escola Paulista de Medicina, Universidade Federal de São Paulo, São Paulo.

Nestadt, G. et al. A family study of obsessive-compulsive disorder. Arch. Gen. Psychiatry, v. 57, p. 358-63, 2000a.

Complex segregation analysis provides compelling evidence for a major gene underlying obsessive-compulsive disorder and for heterogenicity of sex. Am. J. Hum. Genet., v. 67, p. 1611-6, 2000b.

The identification of OCD-related subgroups based on comorbidity. Biol. Psychiatry, v. 53, n. 10, p. 914-20, 2003 May 15.

Nicolini, H. et. al. Segregation analysis of obsessive-compulsive and related disorders. Preliminary results. Ursus. Med., v. 1, p. 25-8, 1991.

Patarroyo, M. E. et al. Association of a B cell alloantigen with susceptibility to Rheumatic fever. Nature. London, v. 278, p. 173-4, 1979.

Pato, M. T. et al. Recent findings ine the genetics of OCD. Review. J. Clin. Psychiatry., v. 63, suppl 6, p. 30-3, 2002.

Pauls, D. L. et al. A family study of obsessive-compulsive disorder. Am. J. Psychiatry., v. 152, p. 76-84, 1995. 
Perugi, G. et al. The clinical impact of bipolar and unipolar affective comorbidity on obsessive-compulsive disorder. J. Affect. Disord., v. 46, n. 1, p. 15-23, 1997.

Phillips, K. A. et al. Effectiveness of pharmacotherapy for body dysmorphic disorder: a chart-review study. J. Clin. Psychiatry, v. 62, n. 9, p. 721-7, 2001.

Pitman, R. K. Janet's Obsessions and Psychasthenia: a synopsis. Psychiatric. Quarterly, v. 56, p. 291-314, 1984.

Posttraumatic obsessive-compulsive disorder: a case study. Compr. Psychiatry, v. 34, n. 2, p. 102-27, Mar.-Apr./1993.

Rajarethinam, R. P. et. al. Acute onset and remission of obsessions and compulsions following medical illnesses and stress. Depress. Anxiety, v. 12, n. 4, p. 238-40, 2000.

Rasmussen, A. S. Genetic studies of obsessive-compulsive disorder. Ann. Clin. Psychiatry, v. 5, p. 241-7, 1993.

Rasmussen, A. S. e Eisen, J. L. The epidemiology and clinical features of obsessive compulsive disorder. Psychiatr. Clin. North. Am., v. 15, n. 4, p. 743-58, 1992.

Rasmussen, S. e Tsuang, M. Epidemiology of obsessive-compulsive disorder. J. Clin. Psychiatry, v. 45, p. 450-7, 1984.

et Clinical characteristics and family history in DSM-III obsessivecompulsive disorder. Am. J. Psychiatry, v. 143, p. 317-22, 1986.

RicCIARDI, J. N. et al. Changes in DSM-III-R axis II diagnoses following treatment of obsessive-compulsive disorder. Am. J. Psychiatry, v. 149, n. 6, p. 829-31, Jun./1992.

Rosario-Campos, M. C. et. al. A family study of early-onset obsessive-compulsive disorder. Am. J. Med. Genet. B. Neuropsychiatr. Genet., v. 136, n. 1, p. 92-7, 2005.

Rothemberg, A. Adolescence and eating disorder: the obsessive-compulsive syndrome. Psych. Clin. North. Am., v. 13, n. 3, p. 469-88, 1990.

SAsson, Y. et al. Posttraumatic obsessive-compulsive disorder: A case series. Psychiatry Research., v. 135, p. 145-52, 2005.

Sichel, D. A. et al. Postpartum obsessive compulsive disorder: a case series. J. Clin. Psychiatry, v. 54, n. 4, p. 156-9, Apr./1993.

Simpson, S. e Baldwin, B. Neuropsychiatry and SPECT of an acute obsessivecompulsive syndrome patient. Br. J. Psychiatry, v. 166, n. 3, p. 390-2, Mar./1995.

STANFORD School of Medicine. Obsessive-compulsive and related disorders research program: historic. <http://ocd.stanford.edu/treatment/history.html>

SAVAGE, C. R. et al. Organizational strategies mediate nonverbal memory impairment in obsessive-compulsive disorder. Biol. Psychiatry, v. 45, n. 7, p. 905-16, Apr./1999. 
Strategic processing and episodic memory impairment in obsessive compulsive disorder. Neuropsychology, v. 14, n. 1, p. 141-51, Jan./2000.

Swedo, S. E. et al. Sydenham's Chorea: physical and psycological symptoms of St. Vitus dance. Pediatrics, v. 91, n. 4, p. 706-13, 1993.

Swoboda, K. J. e Jenike, M. A. Frontal abnormalities in a patient with obsessivecompulsive disorder: the role of structural lesions in obsessive-compulsive behavior. Neurology, v. 45, n. 12, p. 2130-4, 1995.

Tavares, H. et al. Transtornos alimentares e Transtorno Obsessivo-Compulsivo. In: Miguel, Eurípedes C. Transtornos do espectro obsessivo-compulsivo - Diagnóstico e tratamento. Rio de Janeiro: Guanabara-Koogan, p. 124-37, 1996.

Thiel, A. et al. Thirty-month outcome in patients with Anorexia or Bulimia Nervosa and concomitante obsessive-compulsive disorder. Am. J. Psychiatry, v. 155, n. 2, p. 244-9, 1998.

Torres, Albina Rodrigues. Figura e fundo: um estudo de comorbidade do distúrbio obsessivo-compulsivo e distúrbios da personalidade. 1994. Tese (doutorado em Psiquiatria). Escola Paulista de Medicina, São Paulo.

Torres, A.R. et al. Body dysmorphic disorder: an alternative expression of obsessivecompulsive disorder? Rev. Bras. Psiquiatr., v. 27, n. 2, p. 95-6, Jun./2005.

UrRACA, N. et. al. Mu opioid receptor gene as a candidate for the study of obsessivecompulsive disorder with and without tics. Am. J. Med. Genet. B. Neuropsychiatr. Genet., v. 127, p. 94-6, 2004.

Vallejo, J. Relación de los transtornos obsesivos con otras patologías psíquicas. In: Vallejo, J. e Berrios, G. E. Estados obsesivos. 2. ed. Madrid: Masson, 1995. p. 71-90.

Von Ranson, K. M. et. al. Obsessive-compulsive disorder symptons before and after recovery from bulimia nervosa. Am. J. Psychiatry, v. 156, n. 11, p. 1703-8, 1999.

Westphal, K. Uber Zwangsvorstellungen. Arch. Psychiatr. Nervenkrank, v. 8, 1878, p. 734-50.

Willour, V. L. et al. Replication study supports evidence for linkage to 9p24 in obsessive-compulsive disorder. Am. J. Hum. Genet., v. 75, p. 508-13, 2004.

World Health Organization. The ICD-10 Classification of Mental and Behavioral Disorders: Clinical Descriptions and Diagnostic Guidelines. Geneva, Switzerland: World Health Organization, 1992.

ZAI, G. et al. Myelin oligodendrocyte glycoprotein (MOG) gene is associated with obsessive-compulsive disorder. Am. J. Med. Genet. B. Neuropsychiatr. Genet., v. 129,, p. 64-8, 2004. 
Evidence for the gamma-amino-butyric acid type B receptor 1 (GABBR1) gene as a susceptibility factor in obsessive-compulsive disorder. Am. J. Med. Genet. B. Neuropsychiatr. Genet., v. 134, p. 25-9, 2005.

\section{Resumos}

Este artículo repasa la literatura sobre el desorden obsesivo-compulsivo con el objetivo de informar el estado actual de la investigación científica en ese tema. Los autores mencionan la literatura internacional y dan énfasis a la investigación nacional, principalmente la investigación de su grupo, el PROTOC - Proyecto Trastornos del espectro Obsesivo-compulsivo.

Palabras claves: Trastorno obsesivo compulsivo, psicopatología, co-morbilidad

Cet article analyse la littérature sur trouble obsessionnel-compulsif et a pour but d'informer sur l'état courant de la recherche scientifique sur ce thème. Les auteurs citent la littérature internationale pour mettre en relief la recherche nationale, surtout la recherche de leur groupe, le PROTOC - le Projet des Troubles du Spectre Obsessionnelcompulsif.

Mots clés: Trouble obsessionnel-compulsif, psychopathologie, co-morbidité

This article reviews the literature on obsessive-compulsive disorders with the objective of discussing the current state of the scientific research on this topic. The authors refer to the international literature and stress Brazilian research, especially that carried out by their own group, PROTOC (Obsessive-Compulsive Spectrum Disorders Project).

Key words: Obsessive-compulsive disorder, psychopathology, comorbidity

Versão inicial recebida em setembro de 2006

Versão revisada recebida em janeiro de 2007 